\title{
Safety and efficacy of adjunctive catheter-directed thrombolysis during primary PCI for ST-segment elevation myocardial infarction with high thrombus burden
}

\author{
Satsuki Noma MD 1,2, Hideki Miyachi MD, PhD 1,2,*, Isamu Fukuizumi MD 1,2, Junya Matsuda MD, PhD 1,2, \\ Hideto Sangen MD 1,2, Yoshiaki Kubota MD, PhD 2, Yoichi Imori MD, PhD 1,2, Yoshiyuki Saiki MD, PhD 1,2, \\ Yusuke Hosokawa MD 1,2, Shuhei Tara MD, PhD 1,2, Yukichi Tokita MD, PhD 1,2, Koichi Akutsu, MD, PhD 1,2, \\ Wataru Shimizu MD, PhD 1,2 Takeshi Yamamoto MD, PhD ${ }^{1}$, Hitoshi Takano MD, PhD ${ }^{2}$,
}
1 Division of Cardiovascular Intensive Care, Nippon Medical School Hospital, Tokyo, Japan; satsuki- n@nms.ac.jp (S.N.); isamu-f@nms.ac.jp (I.F.); jun1984087@nms.ac.jp (J.M.); sangen777@nms.ac.jp (H.S.); s9012@nms.ac.jp (Y.I.); s8043@nms.ac.jp (Y.S.); y-hosokawa@nms.ac.jp (Y.H.); s5062@nms.ac.jp (S.T.); koichi- a@nms.ac.jp (K.A); yamamoto56@nms.ac.jp (T.Y.)
2 Department of Cardiovascular Medicine, Nippon Medical School, Tokyo, Japan; ykubota@nms.ac.jp (Y.K.); yukichi@nms.ac.jp (Y.T.); wshimizu@nms.ac.jp (W.S.); htakano@nms.ac.jp (H.T.)
* Correspondence: hidep-@nms.ac.jp (H.M.); Tel.: +81-3-3822-2131

\begin{abstract}
Background: High coronary thrombus burden has been associated with unfavorable outcomes in patients with ST-segment elevation myocardial infarction (STEMI), the optimal management of which has not yet to be established. Methods: We evaluated the safety and efficacy of adjunctive catheter-directed thrombolysis (CDT) during primary percutaneous coronary intervention (PCI) in patients with STEMI and high thrombus burden. Results: Among the 1,849 consecutive patients with STEMI, 263 had high thrombus burden. Moreover, 41 patients received intracoronary infusion of tissue plasminogen activator during primary PCI (CDT group), whereas 222 did not receive (non-CDT group). No significant differences in bleeding complications and in-hospital and long-term mortalities were observed $(9.8 \%$ vs. $7.2 \%$, $\mathrm{p}=0.53 ; 7.3 \%$ vs. $2.3 \%$, $\mathrm{p}=0.11$; and $12.6 \%$ vs. $17.5 \%, \mathrm{p}=0.84$, CDT vs. non-CDT). In patients who underwent antecedent aspiration thrombectomy during PCI (75.6\%; CDT group and 87.4\%; non-CDT group), thrombolysis in myocardial infarction grade 2 or 3 flow rate after thrombectomy was significantly lower in the CDT group than in the nonCDT group $(32.2 \%$ vs. $61.0 \%, \mathrm{p}<0.01)$. However, the final rates improved considerably without significant difference ( $90.3 \%$ vs. $97.4 \%$, $\mathrm{p}=0.14$ ). Conclusions: For STEMI patients with high thrombus burden, adjunctive CDT is safe and effective for improving coronary flow. CDT resulted in favorable coronary flow even after unsatisfactory aspiration thrombectomy.
\end{abstract}

Keywords: high coronary thrombus burden; tissue plasminogen activator; catheter-directed thrombolysis

\section{Introduction}

In patients with ST-segment elevation myocardial infarction (STEMI), the preferred reperfusion regimen is primary percutaneous coronary intervention (PCI) [1, 2]. However, even in cases where primary PCI is needed, high thrombus burden presents difficulties. High thrombus burden is associated with distal embolization, the slow-/no-reflow phenomenon, abrupt closure, stent thrombosis, and poor prognosis [3-6]. The therapeutic strategy for STEMI with high thrombus burden includes intracoronary thrombolysis, 
aspiration thrombectomy, distal embolic protection, excimer laser coronary angioplasty, balloon angioplasty, and stenting. However, interventional cardiologists find it challenging to establish an optimal treatment for high thrombus burden. It has been reported in small case series and studies that intracoronary administration of tissue plasminogen activator (t-PA) reduces coronary thrombus and improves thrombolysis in myocardial infarction (TIMI) flow grade $[7,8]$.

Monteplase (Eisai Co., Ltd, Tokyo, Japan) is a mutant t-PA made by substituting only 1 amino acid in the epidermal growth factor domain and expressed in baby Syrian hamster kidney cells. It has a half-life of $>20$ minutes, which is long compared with the native t-PA half-life of 4 minutes [9], and it can be administered intravenously by a bolus injection. Kawai et al. reported that a single bolus injection of monteplase produces a higher rate of early recanalization of infarct-related coronary arteries than native t-PA [10]. Moreover, several studies have reported the usefulness of intravenous monteplase before PCI in the treatment of acute myocardial infarction $[9,11]$. However, t-PA is known to cause paradoxical activation of thrombin, clot formation, and bleeding. Therefore, current guidelines recommend fibrinolytic therapy including t-PA within 12 hours of symptom onset if primary PCI cannot be performed within 120 minutes after the diagnosis of STEMI. A recent T-time study showed that adjunctive low-dose intracoronary alteplase administered during primary PCI does not reduce microvascular obstruction in patients with STEMI within 6 hours of symptom onset [12]. However, it is unclear if catheter-directed thrombolysis (CDT) using intracoronary monteplase during primary PCI constitute effective treatment for patients with STEMI and high thrombus burden. Thus, the aim of this study was to evaluate the safety and efficacy of adjunctive CDT during primary PCI in patients with STEMI and high thrombus burden and to identify suitable candidates for this therapy.

\section{Materials and Methods}

\subsection{Study protocol}

Between January 2005 and December 2017, 1,849 consecutive patients with STEMI were transferred to Nippon Medical School Hospital, Tokyo, Japan, and they underwent primary PCI. We found that 263 of these patients had high thrombus burden (i.e., an intracoronary thrombus of length $>2 \mathrm{~cm}$ ). Of the 263 patients, 41 were administered adjunctive CDT with intracoronary infusion of t-PA (monteplase) during primary PCI (CDT group) and 222 were not administered the adjunctive therapy during primary PCI (nonCDT group). The diagnosis of STEMI was based on findings of characteristic symptoms of myocardial ischemia, electrocardiographic change (ST-segment elevation in at least 2 contiguous leads and new-onset complete left bundle branch block), and subsequent release of biomarkers of myocardial necrosis [2]. Following STEMI diagnosis and provision of informed consent, all patients underwent primary PCI according to guideline-based practices with the early use of concomitant antiplatelet and anticoagulant medications. Antiplatelet therapy consisted of aspirin and a thienopyridine derivative (clopidogrel, prasugrel, or ticlopidine). With regard to anticoagulant therapy, intravenous unfractionated heparin $(100 \mathrm{U} / \mathrm{kg})$ was administered before primary PCI.

High thrombus burden was defined as the presence of an intracoronary thrombus of length $>20 \mathrm{~mm}$ that is visible on angiography. If there was complete obstruction of an infarct-related artery by an angiographic thrombus, high thrombus burden was evaluated after minimal coronary flow was recovered after wire cross, aspiration thrombectomy, or balloon angioplasty. In our criteria, high thrombus burden corresponded to TIMI thrombus grades 4 (i.e., definite thrombus with the largest dimension $\geq 2$ vessel diameters) and 5 (i.e., total occlusion) [13]. The PCI strategy was dependent on individual interventional cardiologists, and monteplase was administered according to investigator judgment.

The following data were collected and compared between the 2 groups: medical history, coronary risk factors, clinical characteristics, coronary angiographic findings, therapeutic strategies, PCI procedures, TIMI flow grades, myocardial blush grade, corrected 
TIMI frame count, bleeding complications, major adverse cardiac events (MACEs), inhospital mortality, and long-term mortality. Coronary blood flow was defined by TIMI flow grade and corrected TIMI frame count (cTFC) [14, 15]. Myocardial blush grade was measured as the parameter of myocardial reperfusion after PCI [16]. Data on bleeding complication as defined using TIMI bleeding criteria were collected [17]. TIMI major bleeding was defined as bleeding leading to death, intracranial bleeding, or a decrease in hemoglobin level greater than $5 \mathrm{~g} / \mathrm{dL}$ from baseline. TIMI minor bleeding was defined as spontaneous and observed blood loss with a decrease in hemoglobin level greater than 3 $\mathrm{g} / \mathrm{dL}$ but less than $5 \mathrm{~g} / \mathrm{dL}$ from baseline or unobserved blood loss with a decrease in hemoglobin level greater than $4 \mathrm{~g} / \mathrm{dL}$ but less than $5 \mathrm{~g} / \mathrm{dL}$ from baseline [18]. MACE was defined as all causes of death, reinfarction, and ischemia-driven target vessel revascularization.

\subsection{Statistical analysis}

All continuous variables are presented as means and standard deviations. Categorical variables are presented as numbers or percentages. Categorical variables were tested using the chi-square test or Fisher's exact test. Continuous variables were tested using Student's t-test or the Mann-Whitney U test. To evaluate MACE and long-term mortality, we compared the Kaplan-Meier curve using the log-rank test. Propensity score matching analysis was performed to assess the association between t-PA and outcomes to balance for risk factors. A propensity score for t-PA was generated based on a multivariable logistic regression model using the following variables: age, sex, body mass index, Killip class, hypertension, dyslipidemia, diabetes mellitus, smoking, prior myocardial infarction history of PCI, old cerebral infarction, heart failure, and hemodialysis. Propensity score matching was conducted using 4-digit nearest neighbor matching with a 0.20 caliper and a 1:1 match ratio. Values of $p<0.05$ were considered to be statistically significant. All statistical analyses were performed using IBM SPSS statistics 26 (IBM Corporation, Armonk, NY, USA).

\section{Results}

\subsection{Study population}

Data on the baseline characteristics of the CDT and non-CDT groups are shown in Table 1. The CDT group had a higher percentage of men and a lower mean age than the non-CDT group. There were no significant differences in blood pressure, heart rate, maximum creatine kinase level, and maximum creatine kinase-MB level between the 2 groups. The usage rates of aspirin, thienopyridine derivatives, and unfractionated heparin were similar between the 2 groups. A similarly high proportion of patients in both groups had coronary risk factors.

Table 1. Patients' Clinical Characteristics

\begin{tabular}{lccc}
\hline & $\begin{array}{l}\text { CDT group } \\
(\mathrm{n}=41)\end{array}$ & $\begin{array}{l}\text { non-CDT group } \\
(\mathrm{n}=222)\end{array}$ & P value \\
\hline Age (years) & $59.4 \pm 12.8$ & $66.9 \pm 13.0$ & $<0.01$ \\
Male (\%) & 92.7 & 73.0 & $<0.01$ \\
BMI (kg/m²) & $25.1 \pm 4.8$ & $24.2 \pm 3.8$ & 0.20 \\
Systolic BP (mmHg) & $118.5 \pm 32.9$ & $120.3 \pm 31.2$ & 0.77 \\
Diastolic BP (mmHg) & $68.6 \pm 20.4$ & $68.9 \pm 19.7$ & 0.94 \\
HR (beats/min) & $76.1 \pm 23.4$ & $77.4 \pm 20.5$ & 0.77 \\
EF (\%) & $57.6 \pm 7.6$ & $49.4 \pm 12.6$ & 0.06 \\
Creatine kinase (CK) & & & \\
Max CK (IU/L) & $3467 \pm 2999$ & $3314 \pm 2649$ & 0.74 \\
Max CKMb (IU/L) & $294 \pm 308$ & $311 \pm 3250.72$ &
\end{tabular}

Cardiovascular history 


\begin{tabular}{lrrr} 
MI (\%) & 17.1 & 13.2 & 0.55 \\
PCI (\%) & 8.6 & 14.7 & 0.42 \\
CABG surgery (\%) & 2.9 & 1.5 & 0.50 \\
Heart failure (\%) & 2.9 & 1.5 & 0.50 \\
Cerebral infarction (\%) & 11.4 & 10.3 & 0.77 \\
Hemodialysis (\%) & 0.0 & 1.5 & 1.00 \\
PAD (\%) & 2.9 & 1.5 & 0.50 \\
Coronary risk factor & & & \\
Hypertension (\%) & 58.5 & 74.8 & 0.03 \\
Dyslipidemia (\%) & 53.7 & 56.8 & 0.71 \\
Diabetes mellitus (\%) & 24.4 & 31.1 & 0.39 \\
Smoking (\%) & 63.4 & 62.2 & 0.88 \\
Hyperuricemia (\%) & 19.8 & 19.5 & 0.46 \\
Killip classification & & & \\
Class 1 (\%) & 70.7 & 74.3 & 0.85 \\
Class 2 (\%) & 14.6 & 10.8 & \\
Class 3 (\%) & 4.9 & 6.8 & \\
Class 4 (\%) & 9.8 & 8.1 & 0.20 \\
Medication before primary PCI & & & \\
Aspirin (\%) & 100 & 97.1 & \\
Thienopyridine (\%) & 97.1 & 97.1 & 100 \\
Unfractionated heparin & 97.1 & & \\
\hline
\end{tabular}

CDT, catheter-directed thrombolysis; BMI, body mass index; BP, blood pressure; HR, heart rate; $\mathrm{EF}$, ejection fraction; $\mathrm{CK}$, creatine kinase; $\mathrm{MI}$, myocardial infarction; $\mathrm{PCI}$, percutaneous coronary intervention; $\mathrm{CABG}$, coronary artery bypass grafting; $\mathrm{PAD}$, peripheral artery disease

\subsection{Angiographic findings, procedural data, outcomes, and complications}

Data on angiographic findings, PCI technical procedures, and TIMI flow grade before and after PCI are shown in Table 2. About $68 \%$ of culprit lesions in the CDT group and $57.2 \%$ of the culprit lesions in the non-CDT group were found in the right coronary artery (RCA). With regard to PCI procedures, a significantly higher contrast medium volume was used in the CDT group than in the non-CDT group $(219.0 \pm 56.9 \mathrm{~mL}$ vs. $182.1 \pm 64.0$ $\mathrm{mL}, \mathrm{p}=0.02)$. Radiation time was significantly longer in the CDT group than in the nonCDT group ( $45.0 \pm 26.4$ minutes vs. $35.3 \pm 21.8$ minutes, $\mathrm{p}=0.02)$. To remove intracoronary thrombi and improve coronary flow, various technical procedures were used. Aspiration thrombectomy was performed in over $90 \%$ of patients in both groups. The use frequency of intra-aortic balloon pump (IABP) was significantly higher in the CDT group than in the non-CDT group $(41.5 \%$ vs. $21.2 \%, \mathrm{p}<0.01)$. There were no significant differences in the use of distal protection devices $(19.5 \%$ vs. $21.6 \%, p=0.76)$ and intracoronary administration of nitroprusside or nicorandil $(24.4 \%$ vs. $15.8 \%, p=0.18)$. Significantly fewer stents were used in the CDT group than in the non-CDT group $(58.5 \%$ vs. $96.8 \%, \mathrm{p}<0.01)$.

Table 2. Angiographic findings, PCI procedures, and Outcomes

\begin{tabular}{lccc}
\hline & $\begin{array}{l}\text { CDT group } \\
(\mathrm{n}=41)\end{array}$ & $\begin{array}{l}\text { non-CDT group } \\
(\mathrm{n}=222)\end{array}$ & P value \\
\hline Culprit lesion & & & \\
RCA (\%) & 68.3 & 57.2 & \\
LAD (\%) & 24.4 & 35.1 & \\
LCX (\%) & 7.3 & 6.3 & \\
LMT (\%) & 0.0 & 1.3 & \\
PCI procedure & & & \\
Devices & &
\end{tabular}




$\begin{array}{lrrr}\text { Aspiration thrombectomy (\%) } & 90.2 & 93.2 & 0.50 \\ \text { Stent (\%) } & 58.5 & 96.8 & <0.01 \\ \text { Distal protection (\%) } & 19.5 & 21.6 & 0.76 \\ \text { Vasodilator i.c. (\%) } & 24.4 & 15.8 & 0.18 \\ \text { IABP (\%) } & 41.5 & 21.2 & <0.01\end{array}$

\section{Contrast medium}

Dose $(\mathrm{ml})$
Radiation time (min)

TIMI flow grade before PCI

$0(\%)$

$1(\%)$

$2(\%)$

$3(\%)$

TIMI flow grade after PCI

$0(\%)$

$1(\%)$

$2(\%)$

$3(\%)$

Brush score after PCI

\begin{tabular}{cc}
$0(\%)$ & 19.5 \\
$1(\%)$ & 17.1 \\
$2(\%)$ & 36.6 \\
$3(\%)$ & 26.8 \\
\hline tcomes &
\end{tabular}

\section{Outcomes}

In-hospital mortality (\%)

long-term mortality (\%)

\section{Bleeding complications}

TIMI major bleeding (\%)

TIMI minor bleeding (\%)
$219.0 \pm 56.9$
$45.0 \pm 26.4$

92.7

4.9

0.0

2.4

9.7

7.3

31.7

51.2

19.5

17.1

36.6

26.8

7.3
12.6

4.9

9.8
$182.1 \pm 64.0$

0.02

$35.3 \pm 21.8 \quad 0.02$

89.6

5.4

3.6

1.4

0.0

1.8

1.3

86.9

10.4

8.6

26.1

55.0

PCI, percutaneous coronary intervention; RCA, right coronary artery; LAD, left anterior descending artery; LCX, left circumflex; LMT, left main trunk; IABP, intra-aortic balloon pump; Vasodilator*, Nitroprusside or Nicorandil; i.c., intra-coronary; TIMI, thrombolysis in myocardial infarction

Intracoronary monteplase was administered at a mean dose of 702,439 $\pm 519,850 \mathrm{U}$. The median dose was 400,000 U (Figure 1). Intracoronary monteplase was administered using a guiding catheter $(n=24)$ and other catheters such as microcatheters and aspiration catheters (Lumine infusion catheter: $\mathrm{n}=11$; Thrombuster II or III: $\mathrm{n}=5$; Rebirth: $\mathrm{n}=2$; Eliminate: $\mathrm{n}=1$; Pronto V3: $\mathrm{n}=1$; ST01: $\mathrm{n}=1$ ) (Table 3).

As shown in Table 2, approximately $90 \%$ of patients in both groups had TIMI grade 0 flow before PCI. After PCI, the proportion of patients with TIMI grade $\geq 2$ flow increased from $5.0 \%$ to $88.2 \%$ in the non-CDT group and from $2.4 \%$ to $82.9 \%$ in the CDT group. Moreover, there was a significant difference in the distribution of TIMI flow grade after PCI between the 2 groups $(\mathrm{p}<0.01)$. Myocardial blush grade distribution also differed significantly between both groups. Final myocardial blush grade 3 accounted for $55.0 \%$ and $26.8 \%$ in the non-CDT and CDT groups, respectively. 


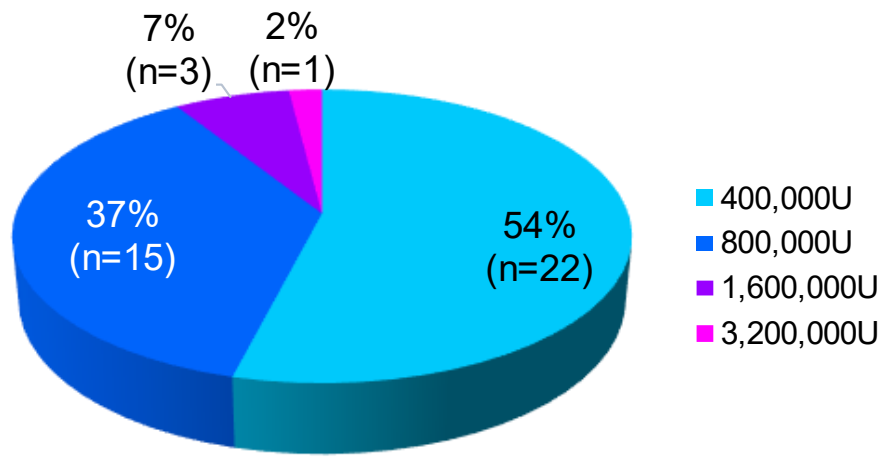

Dose of Monteplase

$(n=41)$

Figure 1. Dose of monteplase administered and proportion of patients

Table 3. t-PA intracoronary administration catheter

\begin{tabular}{lc}
\hline Catheter & N \\
\hline Guiding catheter & 24 \\
Lumine infusion catheter $^{\circledR}$ & 11 \\
Thrombuster II or III $^{\circledR}$ & 5 \\
Rebirth $^{\circledR}$ & 2 \\
Eliminate $^{\circledR}$ & 1 \\
Pronto V3 $^{\circledR}$ & 1 \\
ST01 $^{\circledR}$ & 1 \\
\hline
\end{tabular}

t-PA, tissue plasminogen activator

In-hospital mortality was similar between the 2 groups $(7.3 \%$ versus $2.3 \%, \mathrm{p}=0.11)$ (Table 2), and there was no significant difference in the long-term survival rate between both groups $(87.4 \%$ versus $82.5 \%$, log-rank $\mathrm{p}=0.84$ ) (Figure $2 \mathrm{~A}$ ). Further, there was no significant difference in MACEs between the 2 groups (event-free rate: $80.1 \%$ versus $79.5 \%$, log-rank $\mathrm{p}=0.55$ ) (Figure $2 \mathrm{~B}$ ). The TIMI major and minor bleeding rates were also not significantly different between the 2 groups (Table 2 ). 

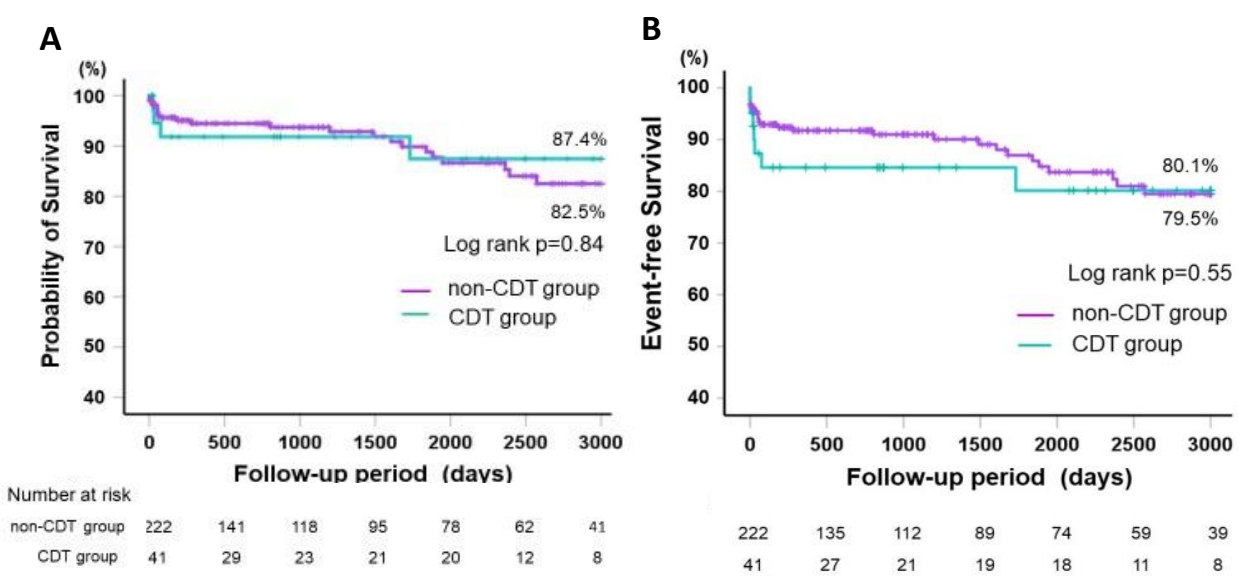

Figure 2. Survival rates and MACE free rates in the CDT and non-CDT groups Kaplan-Meier curves for long-term survival rate and MACE (death, reinfarction, or ischemia-driven target vessel revascularization) free rate in the CDT and non-CDT groups are shown.

CDT, catheter-directed thrombolysis; MACE, major adverse cardiac event

\subsection{Propensity score matching analysis}

Propensity score matching analysis was conducted in selected patients with similar characteristics and comorbidities within each group. After propensity score matching, 68 patients ( 34 in each group) were included. Baseline patient characteristics and medications of the matched groups are shown in Table 4. Both groups matched well for clinical variables, except for left ventricular ejection fraction. Even after propensity score matching analysis, in-hospital mortality, major bleeding, and minor bleeding did not differ significantly between both groups $(7.3 \%$ vs. $2.3 \%, p=0.11 ; 5.9 \%$ vs. $0.9 \%, p=0.49$; and $11.8 \%$ vs. $14.7 \%, \mathrm{p}=1.00$, respectively). The Kaplan-Meier curves for all-cause death revealed no differences in long-term survival rates and MACEs between the CDT and non-CDT group ( $85.6 \%$ vs. $91.4 \%, \log$-rank $\mathrm{p}=0.39,76.9 \%$ vs. $81.3 \%, \log$-rank $\mathrm{p}=0.52$, respectively) (Figure $3)$.

Table 4. Patients' Clinical Characteristics and outcomes after propensity score matching

\begin{tabular}{lccc}
\hline & $\begin{array}{l}\text { CDT group } \\
(\mathrm{n}=34)\end{array}$ & $\begin{array}{l}\text { non-CDT group } \\
(\mathrm{n}=34)\end{array}$ & P value \\
\hline Age (years) & $61.6 \pm 11.9$ & $67.5 \pm 10.3$ & 0.03 \\
Male (\%) & 91.2 & 73.5 & 0.11 \\
BMI (kg/m²) & $25.0 \pm 5.0$ & $24.3 \pm 2.9$ & 0.50 \\
Systolic BP (mmHg) & $126.5 \pm 25.9$ & $122.4 \pm 26.0$ & 0.52 \\
Diastolic BP (mmHg) & $71.6 \pm 17.1$ & $70.5 \pm 16.1$ & 0.79 \\
HR (beats/min) & $76.1 \pm 22.5$ & $78.4 \pm 20.0$ & 0.66 \\
EF (\%) & $57.6 \pm 7.6$ & $47.9 \pm 12.6$ & $<0.01$ \\
Creatine kinase (CK) & & & \\
Max CK (IU/L) & $3509 \pm 3150$ & $3360 \pm 2756$ & 0.44 \\
Max CKMb (IU/L) & $306 \pm 229$ & $267 \pm 197$ & $<0.01$ \\
Cardiovascular history & & & \\
MI (\%) & 20.6 & 14.7 & 0.75 \\
PCI (\%) & 8.8 & 11.8 & 1.00 \\
CABG surgery (\%) & 5.9 & 2.9 & 1.00 \\
Heart failure (\%) & 2.9 & 0.0 & 1.00
\end{tabular}


Cerebral infarction (\%)

Hemodialysis (\%)

PAD (\%)

\section{Coronary risk factor}

Hypertension (\%)

Dyslipidemia (\%)

Diabetes mellitus (\%)

Smoking (\%)

Class $1(\%)$

Class $2(\%)$

Class $3(\%)$

Class $4(\%)$

TIMI flow grade after PCI

$0(\%)$

$1(\%)$

$2(\%)$

$3(\%)$

Myocardial Blush grade after PCI

$\begin{array}{cc}0(\%) & 23.5 \\ 1(\%) & 17.6 \\ 2(\%) & 32.4 \\ 3(\%) & 26.5 \\ \text { C } & 52.0 \pm 30.0\end{array}$

Outcomes

In-hospital mortality (\%)

Bleeding complications

TIMI major bleeding (\%)

TIMI minor bleeding (\%)

\section{Killip classification}

11.8

0.0

2.9

61.8

52.9

26.5

61.8

67.6

17.6

5.9

8.8

11.8

8.8

35.3

44.1

23.5

17.6

26.5

$52.0 \pm 30.0$

7.3

\section{9}

11.8
14.7

0.0

2.9

1.00

1.00

85.3

0.05

61.8

0.62

38.2

0.43

61.8

1.00

70.0

0.94

5.9

17.6

5.9

0.0

0.0

20.6

79.4

\section{7}

14.7

20.6

50.6

$33.8 \pm 17.3$

$<0.01$

2.3

0.11

0.08

$<0.01$

CDT, catheter-directed thrombolysis; BMI, body mass index; BP, blood pressure; HR, heart rate; $\mathrm{EF}$, ejection fraction; $\mathrm{CK}$, creatine kinase; $\mathrm{MI}$, myocardial infarction; $\mathrm{PCI}$, percutaneous coronary intervention; $\mathrm{CABG}$, coronary artery bypass grafting; $\mathrm{PAD}$, peripheral artery disease; TIMI, thrombolysis in myocardial infarction; cTFC, corrected TIMI frame count
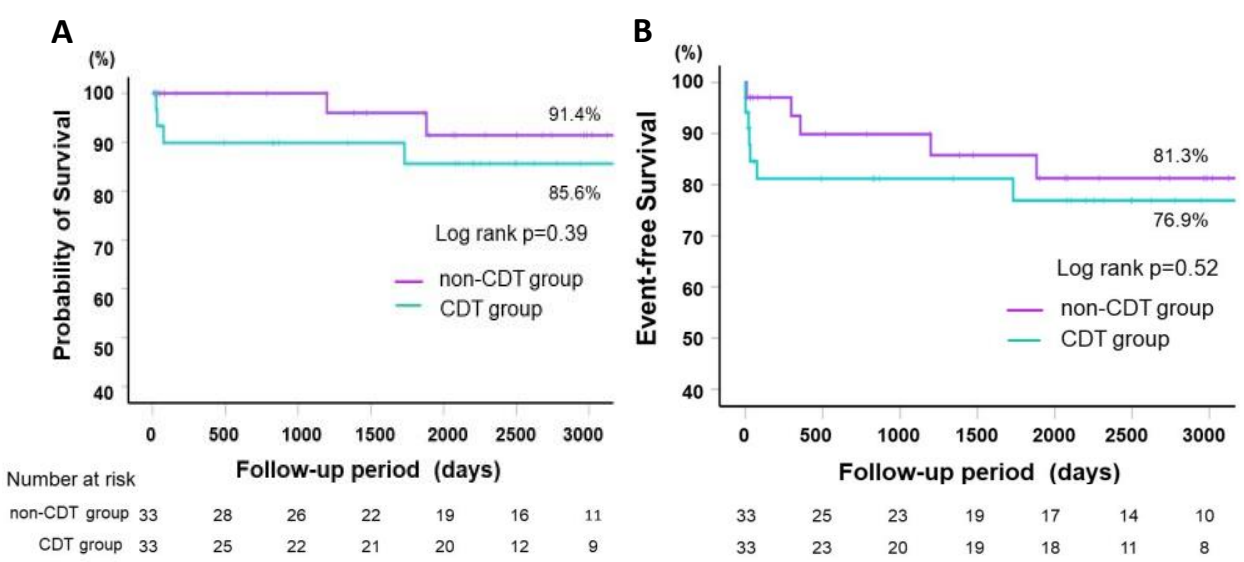

Figure 3. Survival rates and MACE free rates after propensity score matching After propensity score matching, Kaplan-Meier curves for long-term survival rate and MACE (death, reinfarction, or ischemia-driven target vessel revascularization) free rate in the CDT and non-CDT groups are shown.

CDT, catheter-directed thrombolysis; MACE, major adverse cardiac event 


\subsection{Antecedent aspiration thrombectomy cases}

Aspiration thrombectomy was initially performed to remove high thrombus burden in a number of patients (CDT group: $n=31$ [75.6\%]; non-CDT group: $n=194$ [87.4\%]). Subsequently, several therapeutic procedures such as IABP, distal embolic protection, intracoronary vasodilator infusion, and CDT were performed. Therefore, we also analyzed antecedent aspiration thrombectomy cases. In most patients in the CDT group, TIMI flow grade did not improve substantially after aspiration thrombectomy. TIMI flow increased to grade 2 or 3 after aspiration thrombectomy in only $32.0 \%$ of patients in the CDT group (Figure 4). Thereafter, intracoronary t-PA administration and other procedures were added. As a result, most patients (90.0\%) finally had TIMI grade 2 or 3 flow. By contrast, in the non-CDT group, initial aspiration thrombectomy drastically improved TIMI flow grade (TIMI grade 2 or 3 flow: from $4.6 \%$ to 60.8\%). Finally, TIMI grade 2 or 3 flow was achieved in $96.9 \%$ of patients in the non-CDT group, and this was not significantly different compared with that in the CDT group $(\mathrm{p}=0.14)$.

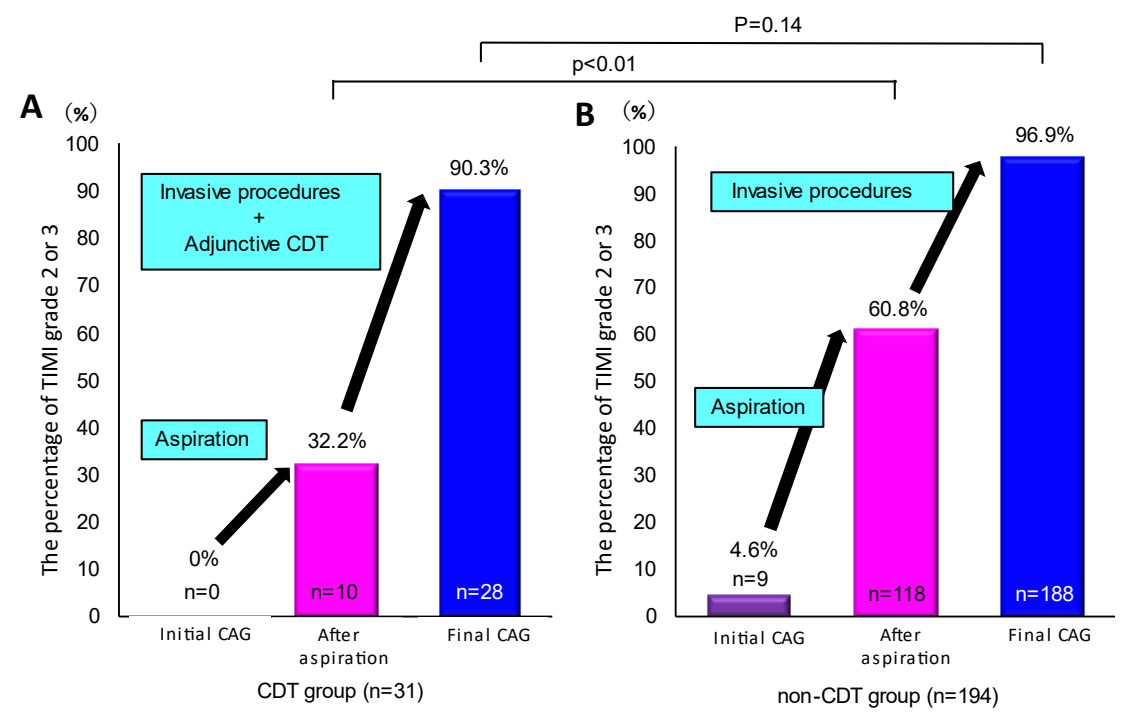

Figure 4. Change of TIMI grade 2 or 3 flow in antecedent aspiration thrombectomy cases We performed subgroup analysis of antecedent aspiration thrombectomy cases (CDT group: $n=31$; non-CDT group: $n=194$ ). Figure 4A shows the rate of TIMI grade 2 or 3 flow during PCI in the CDT group. The rate increased from $0 \%$ to $32 \%$ after aspiration thrombectomy. The rate finally increased to $90.3 \%$ after other invasive procedures and adjunctive CDT. The invasive procedures included IABP, intracoronary vasodilator infusion, distal protection, balloon dilatation, and stent implantation. Figure $4 \mathrm{~B}$ shows the rate of TIMI grade 2 or 3 flow during PCI in the non-CDT group. The rate remarkably increased from $4.6 \%$ to $60.8 \%$ after aspiration thrombectomy. The rate finally improved to $96.9 \%$ after other invasive procedures but without CDT. The rate of TIMI grade 2 or 3 flow after aspiration thrombectomy was lower in the CDT group than in the non-CDT group $(32.2 \%$ versus $60.8 \%, \mathrm{p}<0.01)$. However, the final TIMI grade 2 or 3 flow rate was acceptable and with no statistically significant difference between the 2 groups $(90.3 \%$ versus $96.9 \%, \mathrm{p}=0.14$ ).

TIMI, thrombolysis in myocardial infarction; CDT, catheter-directed thrombolysis; IABP, intra-aortic balloon pump

On the other hand, cTFC distributions were quite different between both groups (Figure 5). At the initial CAG, cTFCs were 100 in most cases within both groups, and no significant differences between both groups were observed $(p=0.70)$. After aspiration thrombectomy, mean cTFC in the non-CDT group drastically decreased and was significantly 
lower than that in the CDT group $(\mathrm{p}<0.01)$. The final median $\mathrm{CTFC}$ in the CDT group also decreased, although it remained higher than that in the non-CDT group $(\mathrm{p}<0.01)$. Additionally, the final CTFC in the CDT group was more widely distributed than that in the non-CDT group.

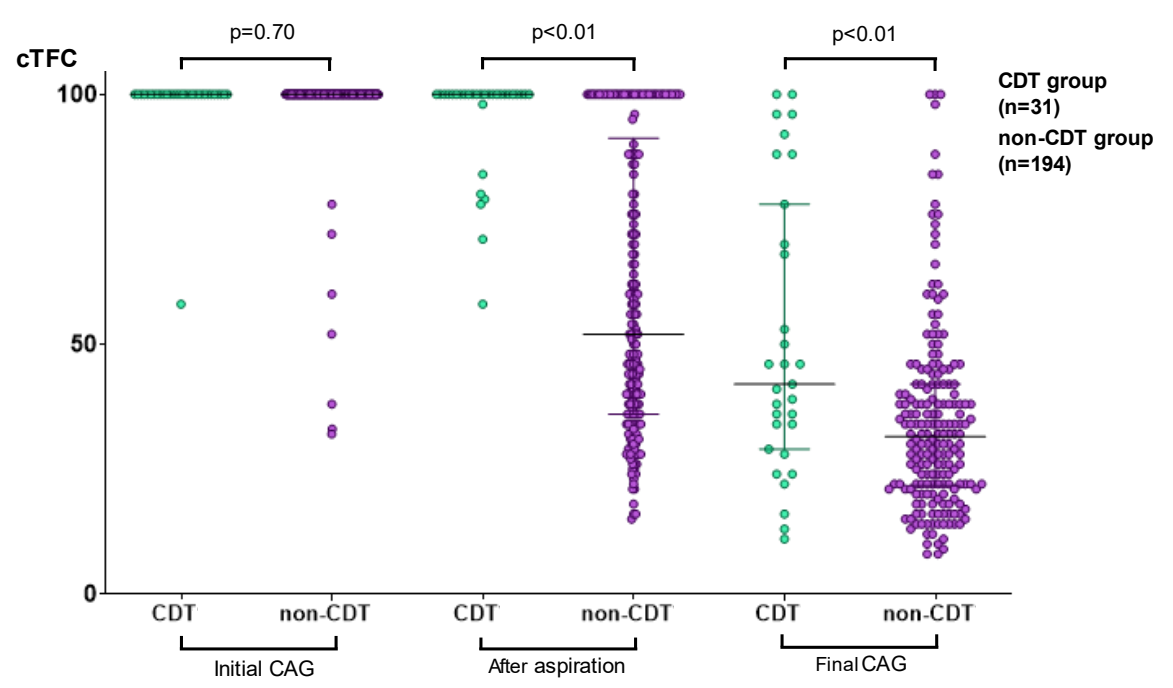

Figure 5. Change of Corrected TIMI Frame Count in antecedent aspiration thrombectomy cases

In antecedent aspiration thrombectomy cases (CDT group: $\mathrm{n}=31$; non-CDT group: $\mathrm{n}=$ 194), figure 4 shows the distribution of CTFC at the initial CAG, after aspiration, and final CAG. At the initial CAG, the median CTFC was 100 in both groups. After aspiration thrombectomy, median cTFC decreased in the non-CDT, which was significantly lower than that in the CDT group (52 [IQR 36-91] vs 100 [100-100], p < 0.01). At the final CAG, cTFCs in both groups decreased to less than 50. Median cTFC in the non-CDT group was lower than that in the CDT group (32 [22-42] vs 42 [29-78], $\mathrm{p}<0.01)$.

TIMI, thrombolysis in myocardial infarction; CDT, catheter-directed thrombolysis;

CTFC, corrected TIMI frame count; CAG, coronary arteriography; IQR, interquartile range

\subsection{Clinical characteristics of patients in the CDT group with final TIMI flow grade 0 or 1}

Despite intracoronary t-PA administration, the final TIMI flow grade of 6 patients with STEMI and high thrombus burden did not improve but remained at grade 0 or 1 . The clinical characteristics of these 6 patients are shown in Table 5. All the patients were men, and half of the infarct-related lesions were distal branch lesions (\#4AV lesions in 2 patients and a \#14 lesion in 1 patient). Four patients had plaque rupture lesions, and 2 patients had embolism. One patient died due to ventricular septal perforation (patient 5). An RCA \#3 lesion with TIMI flow grade 0 was the culprit lesion. Owing to the severely tortuous nature of the RCA, devices could not be passed across the lesion. Therefore, the interventional cardiologist administered an intracoronary t-PA injection.

Table 5. Clinical characteristics in STEMI patients with final TIMI 0 or 1 in CDT group

\begin{tabular}{|c|c|c|c|c|c|c|c|c|c|c|}
\hline Case & $\begin{array}{l}\text { Age } \\
\text { (y.o) }\end{array}$ & Sex & IRL & $\begin{array}{c}\text { Prior } \\
\text { MI }\end{array}$ & Killip & $\begin{array}{c}\text { Lesion } \\
\text { characteristics }\end{array}$ & $\begin{array}{c}\text { The reason of t-PA } \\
\text { administration }\end{array}$ & $\begin{array}{c}\text { Other therapeutic } \\
\text { strategies }\end{array}$ & $\begin{array}{l}\text { Initial } \\
\text { TIMI } \\
\text { grade }\end{array}$ & Death \\
\hline
\end{tabular}




\begin{tabular}{|c|c|c|c|c|c|c|c|c|c|c|}
\hline 1 & 71 & $\mathrm{M}$ & $\begin{array}{l}\text { LAD } \\
(\# 7)\end{array}$ & - & 3 & Embolism & $\begin{array}{l}\text { Unsuccessful } \\
\text { thrombectomy }\end{array}$ & $\begin{array}{c}\text { Thrombectomy } \\
\text { IABP }\end{array}$ & 1 & - \\
\hline 2 & 70 & $\mathrm{M}$ & $\begin{array}{c}\mathrm{RCA} \\
(4 \mathrm{AV})\end{array}$ & - & 1 & Embolism & $\begin{array}{l}\text { Peripheral lesion } \\
\text { unsuitable for PCI }\end{array}$ & - & 0 & - \\
\hline 3 & 67 & $\mathrm{M}$ & $\begin{array}{l}\mathrm{LCX} \\
(\# 14)\end{array}$ & - & 1 & $\begin{array}{l}\text { Plaque } \\
\text { rupture }\end{array}$ & $\begin{array}{l}\text { Acute stent } \\
\text { thrombosis }\end{array}$ & $\begin{array}{c}\text { Thrombectomy } \\
\text { stenting }\end{array}$ & 0 & - \\
\hline 4 & 58 & $\mathrm{M}$ & $\begin{array}{c}\text { RCA } \\
(4 \mathrm{AV})\end{array}$ & + & 2 & $\begin{array}{l}\text { Plaque } \\
\text { rupture }\end{array}$ & $\begin{array}{c}\text { Guide-wire } \\
\text { induced coronary } \\
\text { dissection }\end{array}$ & Thrombectomy & 1 & - \\
\hline 5 & 70 & $\mathrm{M}$ & $\begin{array}{l}\mathrm{RCA} \\
(\# 3)\end{array}$ & - & 3 & $\begin{array}{l}\text { Plaque } \\
\text { rupture }\end{array}$ & $\begin{array}{c}\text { Devices were } \\
\text { undelivered. } \\
\text { (severe tortuous) }\end{array}$ & IABP & 0 & $\begin{array}{c}+ \\
(\mathrm{VSR})\end{array}$ \\
\hline 6 & 59 & $\mathrm{M}$ & $\begin{array}{l}\mathrm{RCA} \\
(\# 2)\end{array}$ & - & 1 & $\begin{array}{l}\text { Plaque } \\
\text { rupture }\end{array}$ & $\begin{array}{l}\text { Unsuccessful } \\
\text { thrombectomy }\end{array}$ & $\begin{array}{c}\text { Thrombectomy } \\
\text { IABP } \\
\text { stenting }\end{array}$ & 0 & - \\
\hline
\end{tabular}

STEMI, ST-elevation myocardial infarction; t-PA, tissue plasminogen activator; TIMI, thrombolysis in myocardial infarction; IRL, infarct-related lesion; LAD, left anterior descending; RCA, right coronary artery; PCI, percuraneous coronary intervention; LCX, left circumflex; IABP, intra-aortic balloon pump; VSR, Ventricular septal rupture; i.c., Intracoronary

\section{Discussion}

This study revealed several important findings. First, adjunctive CDT during primary PCI improved coronary flow and resulted in favorable outcomes in patients with STEMI and high thrombus burden; however, the outcomes were not superior to those of patients who did not require adjunctive CDT. Safety, including bleeding complications, was significantly similar between both groups. In patients who underwent antecedent aspiration thrombectomy, those in the CDT group had poorer coronary flow after thrombectomy evaluated by TIMI flow grade and CTFC compared to those in the non-CDT group. However, the final coronary flow dramatically improved, and TIMI flow grade 2 or 3 rate was similar between both groups. The results of this study show that adjunctive CDT improves finally coronary flow even in cases of failed aspiration thrombectomy.

Historically, urokinase, streptokinase, and t-PA have been used as thrombolysis options. In a previous study in which intracoronary urokinase was administered after thrombus development during PCI, there was no reported in-hospital death, but $10 \%$ of the patients required blood transfusions [19]. The results of the Thrombolysis and Angioplasty in Unstable Angina study and those of several other studies show that the effectiveness of intracoronary urokinase in the treatment of stable and unstable anginas is largely discouraging [20-22]. In the Intracoronary t-PA Registry, the bleeding complication rate of thrombolysis was shown to be high (9.2\%) [23]. As a result, intracoronary thrombolysis is rarely used in clinical practice. Furthermore, there have been advancements in device technologies and pharmacology such as aspiration thrombectomy, distal protection devices, dual antiplatelet therapy, and glycoprotein IIb/IIIa inhibitors [24, 25].

Conversely, the results of several other studies support the usefulness of intracoronary thrombolysis in select cases [7, 23, 26]. It was reported in some case reports that adjunctive CDT during PCI is useful as a therapeutic strategy for high thrombus burden [2730]. In particular, 2 case reports showed that post-intracoronary thrombolytic therapy is a good option for patients who previously underwent failed thrombectomy during primary PCI $[28,29]$. These case findings are consistent with the results of our study. In our study, 
adjunctive CDT was administered to patients whose coronary flow could not be improved using aspiration thrombectomy. Post-procedurally, the adjunctive CDT strategy led to favorable outcomes, and final coronary flow was almost similar to those of the non-CDT strategy. Therefore, adjunctive CDT may be an option for cases of high thrombus burden in which coronary flow does not improve after aspiration thrombectomy.

Recent studies have revealed the unusefulness of intracoronary thrombolysis in microvascular obstruction due to distal embolization of the thrombus [31-33]. Although the current study showed that intracoronary thrombolysis improved the coronary flow, a few cases still had slow flow or no reflow. In such cases, poor coronary flow may be attributed to microvascular obstruction due to distal embolism from proximal high thrombus burden. Moreover, adjunctive CDT has some safety concerns, such as bleeding complications. However, previous studies have shown that intracoronary thrombolysis did not increase the bleeding risk. The current study also found no difference in bleeding complication between both groups, despite varying dose of monteplase in each case.

The clinical characteristics of patients in the CDT group with final TIMI grade 0 or 1 flow are shown in Table 4. RCA and/or distal lesions accounted for 4 of $6(66 \%)$ cases of infarct-related lesions. Thus, even with adjunctive CDT, it may be difficult to obtain good TIMI flow in the case of an RCA lesion with high thrombus burden at the distal branch. To prevent the no-reflow phenomenon, it is important to reduce thrombus burden using thrombectomy devices or other means. However, recent large-scale studies and metaanalyses indicated that routine thrombus aspiration during PCI for STEMI increases the risk of stroke and/or transient ischemic attack and does not improve clinical outcomes [34-37]. Therefore, routine thrombus aspiration is not recommended in recent guidelines [2]. However, in a previous study, the subgroup analysis of patients with high thrombus burden (i.e., TIMI thrombus grade $\geq 3$ ) suggested that thrombus aspiration improves cardiovascular mortality [38]. Thus, it seems reasonable that several of our patients with high thrombus burden underwent initially aspiration thrombectomy. In addition, it was reported in the ASSENT-4 PCI trial that, compared with primary PCI, full-dose tenecteplase combined with PCI is associated with an increase in the primary end point of death, congestive heart failure, or shock within 90 days [39]. Thus, adjunctive CDT during PCI should not be routinely recommended but should be limited to patients with STEMI and high thrombus burden, as shown in this study.

Several important limitations of our study should be noted. First, because this study was a retrospective nonrandomized trial with a small sample size that was performed at a single institute, there may be selection bias. Additionally, other treatment options such as aspiration thrombectomy, distal protection, IABP, and intracoronary nitroprusside or nicorandil may have contributed to the final patient outcomes. Second, thrombus burden was higher in this study than in other studies. Previous studies defined high thrombus burden as the presence of accumulated thrombus $>3$ times the luminal diameter of the infarct-related artery or TIMI thrombus grade $>3$ [6] [40]. By contrast, we defined high thrombus burden as the presence of an intracoronary thrombus of length $>20 \mathrm{~mm}$ that is visible on angiography and corresponds to TIMI thrombus grade $>4$. This difference may underestimate the effectiveness of adjunctive CDT. In contrast, detailed quantitative evaluation of thrombus burden was not performed in this study. Adjunctive CDT depends on interventional cardiologists' judgment. Thus, thrombus burden size may be associated with effectiveness of adjunctive CDT strategy. Third, because the efficacy of an intravenous bolus injection of abciximab in the prevention of post-PCI coronary events in Japanese patients has not been confirmed, the glycoprotein $\mathrm{IIb} / \mathrm{III}$ a receptor antagonist is not available in Japan and was not used in this study. Additionally, the usage rate of the anticoagulation drug was not analyzed in this study; therefore, its effect may be underestimated. Finally, the pathophysiology of STEMI such as plaque rupture, plaque erosion, or calcified nodules, was not considered in this study, which may have had an effect on the results. These limitations deserve confirmation in a large randomized controlled trial.

\section{Conclusion}


Adjunctive CDT during primary PCI is safe and produces acceptable outcomes in patients with STEMI and high thrombus burden. It may be a useful therapeutic option in cases of high thrombus burden in which coronary flow cannot be significantly improved using aspiration thrombectomy.

Author Contributions: H.M. and T.Y. designed this study. S.N., I.F., J.M., H.S., Y.K., Y.I., Y.S., Y.H., S.T., Y.T., and K.A performed the data acquisition. S.N., H.M., and T.Y. analyzed and interpretated the data. S.N. and H.M. performed the statistical analysis. T.Y. was involved in the critical revision of the manuscript. W.S. and H.T. approved the final version prior to submission. All authors have read and agreed to the published version of the manuscript.

Funding: This research received no grant from any funding agency in the public, commercial, or not-for-profit sector.

Institutional Review Board Statement: This study was approved by the Nippon Medical School Hospital Ethics Committee (Reference no. B-2020-242).

Informed Consent Statement: The requirement for informed consent was waived because all data were anonymized.

Data Availability Statement: The data presented in this study are available on request from the corresponding author.

Acknowledgments: The authors thank all those who have been involved with patient care, including emergency medical services, technicians, medical engineers, nurses, pharmacists, and physicians, in Nippon Medical School Hospital.

Conflicts of Interest: The authors declare no conflict of interest.

\section{References}

1. Steg, P. G.; James, S. K.; Atar, D.; Badano, L. P.; Blomstrom-Lundqvist, C.; Borger, M. A.; Di Mario, C.; Dickstein, K.; Ducrocq, G.; Fernandez-Aviles, F.; Gershlick, A. H.; Giannuzzi, P.; Halvorsen, S.; Huber, K.; Juni, P.; Kastrati, A.; Knuuti, J.; Lenzen, M. J.; Mahaffey, K. W.; Valgimigli, M.; van 't Hof, A.; Widimsky, P.; Zahger, D. ESC Guidelines for the management of acute myocardial infarction in patients presenting with ST-segment elevation. Eur. Heart. J. 2012, 33, 2569-2619.

2. Ibanez, B.; James, S.; Agewall, S.; Antunes, M. J.; Bucciarelli-Ducci, C.; Bueno, H.; Caforio, A. L. P.; Crea, F.; Goudevenos, J. A.; Halvorsen, S.; Hindricks, G.; Kastrati, A.; Lenzen, M. J.; Prescott, E.; Roffi, M.; Valgimigli, M.; Varenhorst, C.; Vranckx, P.; Widimsky, P. 2017 ESC Guidelines for the management of acute myocardial infarction in patients presenting with ST-segment elevation. Rev. Esp. Cardiol. (Engl Ed). 2017, 70, 1082.

3. Falk, E., Unstable angina with fatal outcome: dynamic coronary thrombosis leading to infarction and/or sudden death. Autopsy evidence of recurrent mural thrombosis with peripheral embolization culminating in total vascular occlusion. Circulation. 1985, 71, 699-708.

4. Singh, M.; Reeder, G. S.; Ohman, E. M.; Mathew, V.; Hillegass, W. B.; Anderson, R. D.; Gallup, D. S.; Garratt, K. N.; Holmes, D. R., Jr., Does the presence of thrombus seen on a coronary angiogram affect the outcome after percutaneous coronary angioplasty? An Angiographic Trials Pool data experience. J. Am. Coll. Cardiol. 2001, 38, 624-630.

5. Sianos, G.; Papafaklis, M. I.; Daemen, J.; Vaina, S.; van Mieghem, C. A.; van Domburg, R. T.; Michalis, L. K.; Serruys, P. W., Angiographic stent thrombosis after routine use of drug-eluting stents in ST-segment elevation myocardial infarction: the importance of thrombus burden. J. Am. Coll. Cardiol. 2007, 50, 573-583.

6. Jolly, S. S.; Cairns, J. A.; Lavi, S.; Cantor, W. J.; Bernat, I.; Cheema, A. N.; Moreno, R.; Kedev, S.; Stankovic, G.; Rao, S. V.; Meeks, B.; Chowdhary, S.; Gao, P.; Sibbald, M.; Velianou, J. L.; Mehta, S. R.; Tsang, M.; Sheth, T.; Dzavik, V.; Investigators, T., Thrombus Aspiration in Patients With High Thrombus Burden in the TOTAL Trial. J. Am. Coll. Cardiol. 2018, 72, 1589-1596. 
7. Crouch, E.; Krumnacher, H.; Cohen, M. G.; Stouffer, G. A., Safety of adjunctive intracoronary thrombolytic therapy during complex percutaneous coronary intervention: initial experience with intracoronary tenecteplase. Catheter. Cardiovasc. Interv. 2005, 66, 327-332.

8. Saito, T.; Taniguchi, I.; Nakamura, S.; Oka, H.; Mizuno, Y.; Noda, K.; Yamashita, S.; Oshima, S., Pulse-spray thrombolysis in acutely obstructed coronary artery in critical situations. Cathet. Cardiovasc. Diagn. 1997, 40, 101-108.

9. Inoue, T.; Yaguchi, I.; Takayanagi, K.; Hayashi, T.; Morooka, S.; Eguchi, Y., A new thrombolytic agent, monteplase, is independent of the plasminogen activator inhibitor in patients with acute myocardial infarction: Initial results of the COmbining Monteplase with Angioplasty (COMA) trial. Am. Heart. J. 2002, 144, H1-H6.

10. Kawai, C.; Yui, Y.; Hosoda, S.; Nobuyoshi, M.; Suzuki, S.; Sato, H.; Takatsu, F.; Motomiya, T.; Kanmatsuse, K.; Kodama, K.; Yabe, Y.; Minamino, T.; Kimata, S.-i.; Nakashima, M., A Prospective, Randomized, Double-Blind Multicenter Trial of a Single Bolus Injection of the Novel Modified t-PA E6010 in the Treatment of Acute Myocardial Infarction: Comparison With Native tPA. J. Am. Coll. Cardiol. 1997, 29, 1447-1453.

11. Kurihara, H.; Matsumoto, S.; Tamura, R.; Yachiku, K.; Nakata, A.; Nakagawa, T.; Yoshino, T.; Matsuyama, T., Clinical outcome of percutaneous coronary intervention with antecedent mutant t-PA administration for acute myocardial infarction. Am. Heart. J. 2004, 147, E14.

12. McCartney, P. J.; Eteiba, H.; Maznyczka, A. M.; McEntegart, M.; Greenwood, J. P.; Muir, D. F.; Chowdhary, S.; Gershlick, A. H.; Appleby, C.; Cotton, J. M.; Wragg, A.; Curzen, N.; Oldroyd, K. G.; Lindsay, M.; Rocchiccioli, J. P.; Shaukat, A.; Good, R.; Watkins, S.; Robertson, K.; Malkin, C.; Martin, L.; Gillespie, L.; Ford, T. J.; Petrie, M. C.; Macfarlane, P. W.; Tait, R. C.; Welsh, P.; Sattar, N.; Weir, R. A.; Fox, K. A.; Ford, I.; McConnachie, A.; Berry, C.; Group, T. T., Effect of Low-Dose Intracoronary Alteplase During Primary Percutaneous Coronary Intervention on Microvascular Obstruction in Patients With Acute Myocardial Infarction: A Randomized Clinical Trial. JAMA. 2019, 321, 56-68.

13. Gibson, C. M.; de Lemos, J. A.; Murphy, S. A.; Marble, S. J.; McCabe, C. H.; Cannon, C. P.; Antman, E. M.; Braunwald, E., Combination therapy with abciximab reduces angiographically evident thrombus in acute myocardial infarction: a TIMI 14 substudy. Circulation. 2001, 103, 2550-2554.

14. Group, T. S., Comparison of invasive and conservative strategies after treatment with intravenous tissue plasminogen activator in acute myocardial infarction. Results of the thrombolysis in myocardial infarction (TIMI) phase II trial. N. Engl. J. Med. 1989, 320, 618-627.

15. Gibson, C. M.; Cannon, C. P.; Daley, W. L.; Dodge, J. T., Jr.; Alexander, B., Jr.; Marble, S. J.; McCabe, C. H.; Raymond, L.; Fortin, T.; Poole, W. K.; Braunwald, E., TIMI frame count: a quantitative method of assessing coronary artery flow. Circulation. 1996, 93, 879-888.

16. van 't Hof, A. W.; Liem, A.; Suryapranata, H.; Hoorntje, J. C.; de Boer, M. J.; Zijlstra, F., Angiographic assessment of myocardial reperfusion in patients treated with primary angioplasty for acute myocardial infarction: myocardial blush grade. Zwolle Myocardial Infarction Study Group. Circulation. 1998, 97, 2302-2306.

17. Chesebro, J. H.; Knatterud, G.; Roberts, R.; Borer, J.; Cohen, L. S.; Dalen, J.; Dodge, H. T.; Francis, C. K.; Hillis, D.; Ludbrook, P.; et al., Thrombolysis in Myocardial Infarction (TIMI) Trial, Phase I: A comparison between intravenous tissue plasminogen activator and intravenous streptokinase. Clinical findings through hospital discharge. Circulation. 1987, 76, 142-154.

18. Rao, A. K.; Pratt, C.; Berke, A.; Jaffe, A.; Ockene, I.; Schreiber, T. L.; Bell, W. R.; Knatterud, G.; Robertson, T. L.; Terrin, M. L., Thrombolysis in Myocardial Infarction (TIMI) Trial--phase I: hemorrhagic manifestations and changes in plasma fibrinogen and the fibrinolytic system in patients treated with recombinant tissue plasminogen activator and streptokinase. J. Am. Coll. Cardiol. 1988, 11, 1-11.

19. Schieman, G.; Cohen, B. M.; Kozina, J.; Erickson, J. S.; Podolin, R. A.; Peterson, K. L.; Ross, J., Jr.; Buchbinder, M., Intracoronary urokinase for intracoronary thrombus accumulation complicating percutaneous transluminal coronary angioplasty in acute ischemic syndromes. Circulation. 1990, 82, 2052-2060.

20. Ambrose, J. A.; Almeida, O. D.; Sharma, S. K.; Torre, S. R.; Marmur, J. D.; Israel, D. H.; Ratner, D. E.; Weiss, M. B.; HjemdahlMonsen, C. E.; Myler, R. K.; et al., Adjunctive thrombolytic therapy during angioplasty for ischemic rest angina. Results of the TAUSA Trial. TAUSA Investigators. Thrombolysis and Angioplasty in Unstable Angina trial. Circulation. 1994, 90, 69-77.

21. DiSciascio, G.; Kohli, R. S.; Goudreau, E.; Sabri, N.; Vetrovec, G. W., Intracoronary recombinant tissue-type plasminogen activator in unstable angina: a pilot angiographic study. Am. Heart. J. 1991, 122 (1 Pt 1), 1-6.

22. Goudreau, E.; DiSciascio, G.; Vetrovec, G. W.; Chami, Y.; Kohli, R.; Warner, M.; Sabri, N.; Cowley, M. J., Intracoronary urokinase as an adjunct to percutaneous transluminal coronary angioplasty in patients with complex coronary narrowings or angioplastyinduced complications. Am. J. Cardiol. 1992, 69, 57-62.

23. Ferguson, J. J., Clinical experience with intracoronary tissue plasminogen activator: results of a multicenter registry. Intracoronary t-PA Registry Investigators. Cathet. Cardiovasc. Diagn. 1995, 34, 196-201.

24. Svilaas, T.; Vlaar, P. J.; van der Horst, I. C.; Diercks, G. F.; de Smet, B. J.; van den Heuvel, A. F.; Anthonio, R. L.; Jessurun, G. A.; Tan, E. S.; Suurmeijer, A. J.; Zijlstra, F., Thrombus aspiration during primary percutaneous coronary intervention. N. Engl. J. Med. 2008, 358, 557-567.

25. Dangas, G.; Stone, G. W.; Weinberg, M. D.; Webb, J.; Cox, D. A.; Brodie, B. R.; Krucoff, M. W.; Gibbons, R. J.; Lansky, A. J.; Mehran, R., Contemporary outcomes of rescue percutaneous coronary intervention for acute myocardial infarction: comparison with primary angioplasty and the role of distal protection devices (EMERALD trial). Am. Heart. J. 2008, 155, $1090-1096$.

26. Gurbel, P. A.; Navetta, F. I.; Bates, E. R.; Muller, D. W.; Tenaglia, A. N.; Miller, M. J.; Muhlstein, B.; Hermiller, J. B.; Davidson, C. J.; Aguirre, F. V.; Beauman, G. J.; Berdan, L. G.; Leimberger, J. D.; Bovill, E. G.; Christenson, R. H.; Ohman, E. M., Lesion- 
directed administration of alteplase with intracoronary heparin in patients with unstable angina and coronary thrombus undergoing angioplasty. Cathet. Cardiovasc. Diagn. 1996, 37, 382-391.

27. Agarwal, S. K., Pharmacoinvasive therapy for acute myocardial infarction. Catheter. Cardiovasc. Interv. 2011, $78,72-75$.

28. Jain, A. K.; Archbold, R. A., Intracoronary thrombolytic therapy: a treatment option for failed mechanical thrombectomy. Catheter. Cardiovasc. Interv. 2012, 80, 835-837.

29. Inaba, S.; Nishimura, K.; Hamagami, T.; Fujita, Y.; Ogimoto, A.; Okayama, H.; Higaki, J., Usefulness of adjunctive pulse infusion thrombolysis after failed aspiration for massive intracoronary thrombus. Can. J. Cardiol. 2011, 27, 869 e1-2.

30. Kim, J. S.; Kim, J. H.; Jang, H. H.; Lee, Y. W.; Song, S. G.; Park, J. H.; Chun, K. J., Successful revascularization of coronary artery occluded by massive intracoronary thrombi with alteplase and percutaneous coronary intervention. J. Atheroscler. Thromb. 2010, $17,768-770$.

31. Gibson, C. M.; Kumar, V.; Gopalakrishnan, L.; Singh, P.; Guo, J.; Kazziha, S.; Devireddy, C.; Pinto, D.; Marshall, J. J.; Stouffer, G. A.; Mavromatis, K.; Grip, L.; Bainey, K. R.; Timi; Group, P. S., Feasibility and Safety of Low-Dose Intra-Coronary Tenecteplase During Primary Percutaneous Coronary Intervention for ST-Elevation Myocardial Infarction (ICE T-TIMI 49). Am. J. Cardiol. 2020, 125, 485-490.

32. Alyamani, M.; Campbell, S.; Navarese, E.; Welsh, R. C.; Bainey, K. R., Safety and Efficacy of Intracoronary Thrombolysis as Adjunctive Therapy to Primary PCI in STEMI: A Systematic Review and Meta-analysis. Can. J. Cardiol. 2021, 37, 339-346.

33. McCartney, P. J.; Eteiba, H.; Maznyczka, A. M.; McEntegart, M.; Greenwood, J. P.; Muir, D. F.; Chowdhary, S.; Gershlick, A. H.; Appleby, C.; Cotton, J. M.; Wragg, A.; Curzen, N.; Oldroyd, K. G.; Lindsay, M.; Rocchiccioli, J. P.; Shaukat, A.; Good, R.; Watkins, S.; Robertson, K.; Malkin, C.; Martin, L.; Gillespie, L.; Ford, T. J.; Petrie, M. C.; Macfarlane, P. W.; Tait, R. C.; Welsh, P.; Sattar, N.; Weir, R. A.; Fox, K. A.; Ford, I.; McConnachie, A.; Berry, C., Effect of Low-Dose Intracoronary Alteplase During Primary Percutaneous Coronary Intervention on Microvascular Obstruction in Patients With Acute Myocardial Infarction: A Randomized Clinical Trial. JAMA. 2019, 321, 56-68.

34. Frobert, O.; Lagerqvist, B.; Olivecrona, G. K.; Omerovic, E.; Gudnason, T.; Maeng, M.; Aasa, M.; Angeras, O.; Calais, F.; Danielewicz, M.; Erlinge, D.; Hellsten, L.; Jensen, U.; Johansson, A. C.; Karegren, A.; Nilsson, J.; Robertson, L.; Sandhall, L.; Sjogren, I.; Ostlund, O.; Harnek, J.; James, S. K., Thrombus aspiration during ST-segment elevation myocardial infarction. N. Engl. J. Med. 2013, 369, 1587-1597.

35. Jolly, S. S.; Cairns, J. A.; Yusuf, S.; Meeks, B.; Pogue, J.; Rokoss, M. J.; Kedev, S.; Thabane, L.; Stankovic, G.; Moreno, R.; Gershlick, A.; Chowdhary, S.; Lavi, S.; Niemela, K.; Steg, P. G.; Bernat, I.; Xu, Y.; Cantor, W. J.; Overgaard, C. B.; Naber, C. K.; Cheema, A. N.; Welsh, R. C.; Bertrand, O. F.; Avezum, A.; Bhindi, R.; Pancholy, S.; Rao, S. V.; Natarajan, M. K.; ten Berg, J. M.; Shestakovska, O.; Gao, P.; Widimsky, P.; Dzavik, V.; Investigators, T., Randomized trial of primary PCI with or without routine manual thrombectomy. N. Engl. J. Med. 2015, 372, 1389-1398.

36. Mastoris, I.; Giustino, G.; Sartori, S.; Baber, U.; Mehran, R.; Kini, A. S.; Sharma, S. K.; Dangas, G. D., Efficacy and safety of routine thrombus aspiration in patients with ST-segment elevation myocardial infarction undergoing primary percutaneous coronary intervention: An updated systematic review and meta-analysis of randomized controlled trials. Catheter. Cardiovasc. Interv. 2016, $87,650-660$.

37. Meneguz-Moreno, R. A.; Costa, J. R., Jr.; Oki, F. H.; Costa, R. A.; Abizaid, A., Thrombus aspiration in STEMI patients: an updated systematic review and meta-analysis. Minerva. Cardioangiol. 2017, 65, 648-658.

38. Jolly, S. S.; James, S.; Dzavik, V.; Cairns, J. A.; Mahmoud, K. D.; Zijlstra, F.; Yusuf, S.; Olivecrona, G. K.; Renlund, H.; Gao, P.; Lagerqvist, B.; Alazzoni, A.; Kedev, S.; Stankovic, G.; Meeks, B.; Frobert, O., Thrombus Aspiration in ST-Segment-Elevation Myocardial Infarction: An Individual Patient Meta-Analysis: Thrombectomy Trialists Collaboration. Circulation. 2017, 135, 143152.

39. Assessment of the, S.; Efficacy of a New Treatment Strategy with Percutaneous Coronary Intervention, i., Primary versus tenecteplase-facilitated percutaneous coronary intervention in patients with ST-segment elevation acute myocardial infarction (ASSENT-4 PCI): randomised trial. Lancet. 2006, 367, 569-578.

40. Echavarria-Pinto, M.; Lopes, R.; Gorgadze, T.; Gonzalo, N.; Hernandez, R.; Jimenez-Quevedo, P.; Alfonso, F.; Banuelos, C.; Nunez-Gil, I. J.; Ibanez, B.; Fernandez, C.; Fernandez-Ortiz, A.; Garcia, E.; Macaya, C.; Escaned, J., Safety and efficacy of intense antithrombotic treatment and percutaneous coronary intervention deferral in patients with large intracoronary thrombus. Am. J. Cardiol. 2013, 111, 1745-1750. 